\title{
Acute bilateral optic/chiasm neuritis with longitudinal extensive transverse myelitis in longstanding stable multiple sclerosis following vector-based vaccination against the SARS-CoV-2
}

\author{
Christoph Helmchen ${ }^{1}$ [D $\cdot$ Gesine M. Buttler ${ }^{1} \cdot$ Robert Markewitz $^{2} \cdot$ Katja Hummel $^{1} \cdot$ Heinz Wiendl $^{3} \cdot$ Tobias Boppel $^{4}$
}

Received: 4 May 2021 / Revised: 2 June 2021 / Accepted: 3 June 2021 / Published online: 15 June 2021

(c) The Author(s) 2021

Dear Sirs,

Multiple sclerosis (MS) and neuromyelitis optica (NMO) are two distinctly different immunological diseases with respect to clinical and MRI signs [4, 10], clinical course, therapy, and pathoimmunology [e.g., antibodies targeting astrocytic water channel aquaporin-4 (AQP4-ab), redefining the variety of clinical NMO as NMO spectrum disorder (NMOSD)] $[10,11]$. Diagnostic criteria are reliable so that both entities should not overlap and must not be confused, e.g., AQP4-ab were only found in $0.33 \%$ of 1183 patients with longstanding MS [3].

We report about a young patient with a longstanding history of relapsing-remittent multiple sclerosis (RRMS) who developed a severe syndrome of optic/chiasm neuritis and paraplegia due to longitudinal extensive transverse myelitis (LETM) [6] resembling NMOSD 2 weeks after her vaccination with the first dose of a vector-based COVID-19 vaccine.

The 40-year-old female patient has a longstanding (21 years) history of RRMS. Diagnosis of RRMS was established in 2000 based on relapsing neurological episodes of different symptoms with variable lesion location (diplopia, paresthesia, paresis of right hand, but no signs of optic neuritis), typical cervical and brain MRI lesions suggestive for

Christoph Helmchen

christoph.helmchen@neuro.uni-luebeck.de

1 Department of Neurology, University of Lübeck, University Hospitals Schleswig Holstein, Campus Lübeck, Ratzeburger Allee 160, 23538 Lübeck, Germany

2 Institute of Clinical Chemistry, University Hospitals Schleswig-Holstein, Campus Lübeck, Kiel, Germany

3 Department of Neurology with Institute of Translational Neurology, University Hospital Münster, Münster, Germany

4 Institute of Neuroradiology, University Hospitals Schleswig-Holstein, Campus Lübeck, Lübeck, Germany
RRMS, and intrathecal oligoclonal bands. Other causes were excluded.

In the first few years, she was treated with interferon and glatiramer acetate and steroid infusions. As she had developed cervical myelitis (at the level C4/5) and continued to suffer from several annual relapses (3-4 x/year), she was put on Natalizumab (NAT) in 2009. Ever since she has had only a few and mild episodes of sensory symptoms but remained functionally independent in daily life. She was repetitively tested negative for antibodies against NAT and JC virus.

Based on the stable disease without severe relapses, she received a vector-based vaccination against SARSCoV-2 in March 2021 (Astra Zeneca, COVID19 Vaccine ${ }^{\circledR}$; Vaxzevria $\left.{ }^{\circledR}\right), 8$ days after the last NAT infusion, and had no immediate adverse events. Two weeks after the vaccination, she noticed blurring of vision which rapidly developed to binocular blindness within $48 \mathrm{~h}$. On day 2 of her blindness, she noticed back pain, mild weakness and numbness in her legs which escalated to the inability to walk within the next $24 \mathrm{~h}$. On day 3 , she was functionally blind and the paraparesis deteriorated to paraplegia, with absent tendon reflexes in the legs, incontinence, and a sensory deficit for all qualities below Th5. CSF showed severe pleocytosis (524 leucocytes $/ \mu 1,98 \%$ neutrophil granulocytes), increased lactate $(6.6 \mathrm{mmol} / \mathrm{l})$ and strongly elevated protein $(2.2 \mathrm{~g} / \mathrm{l})$. Cranial MRI revealed numerous old white matter lesions compatible with MS (in the corpus callosum and periventricular white matter; Fig. 1A, B) and increased signal intensity in the chiasm and part of the adjacent optic nerves and tracts (Fig. 1C, D), MR-morphologically in line with NMOSD. Only mild contrast enhancement of the optic chiasma was observed. Note that there had not been optic nerve/chiasm involvement in previous cranial MRI. Visual-evoked cortical potentials could not be elicited bilaterally. Spinal MRI (1.5T) revealed increased longitudinal centrally located signal intensities throughout the thoracic myelon indicating a myelitis with maximal extent at TH7-10 (Fig. 2A) and in the 


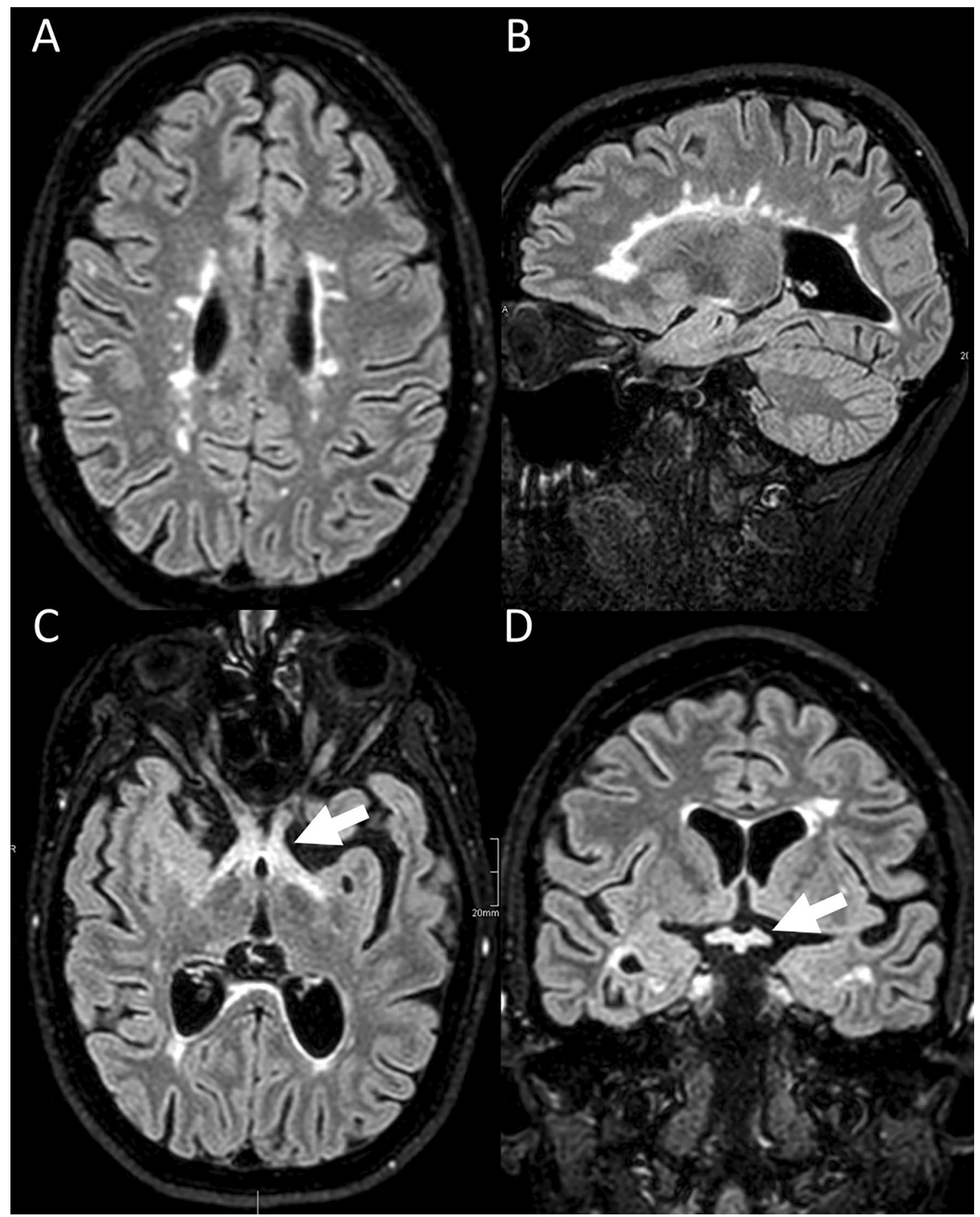

Fig. 1 Cranial MRI (1.5T, FLAIR images) shows an acute inflammatory chiasm lesion (suggestive for NMOSD) in this patient with typical MS lesions. There were numerous chronic periventricular Dawson finger-shaped and ovoid demyelination lesions on axial (A) and sagit-

medullary conus. Mildly elevated signal intensities were also seen at C7-Th1. There were additional residual post-myelitic lesions in the cervical spine (level C4/C5). Two days after having had received methylprednisolone ( $\mathrm{g} /$ day), there was tal (B) fluid-attenuated inversion recovery (FLAIR) images compatible with MS and an increased signal intensity in the chiasm (white arrow) and part of the adjacent optic nerves and optic tract on axial (C) and coronal (D, white arrow) images

no contrast enhancement visible. Initially, there was a slight enlargement of the central canal of the thoracic myelon above the maximal swelling at Th7-10 (Fig. 2A), which subsided in a follow-up MRI 1 week later (Fig. 2B, C). A broad 


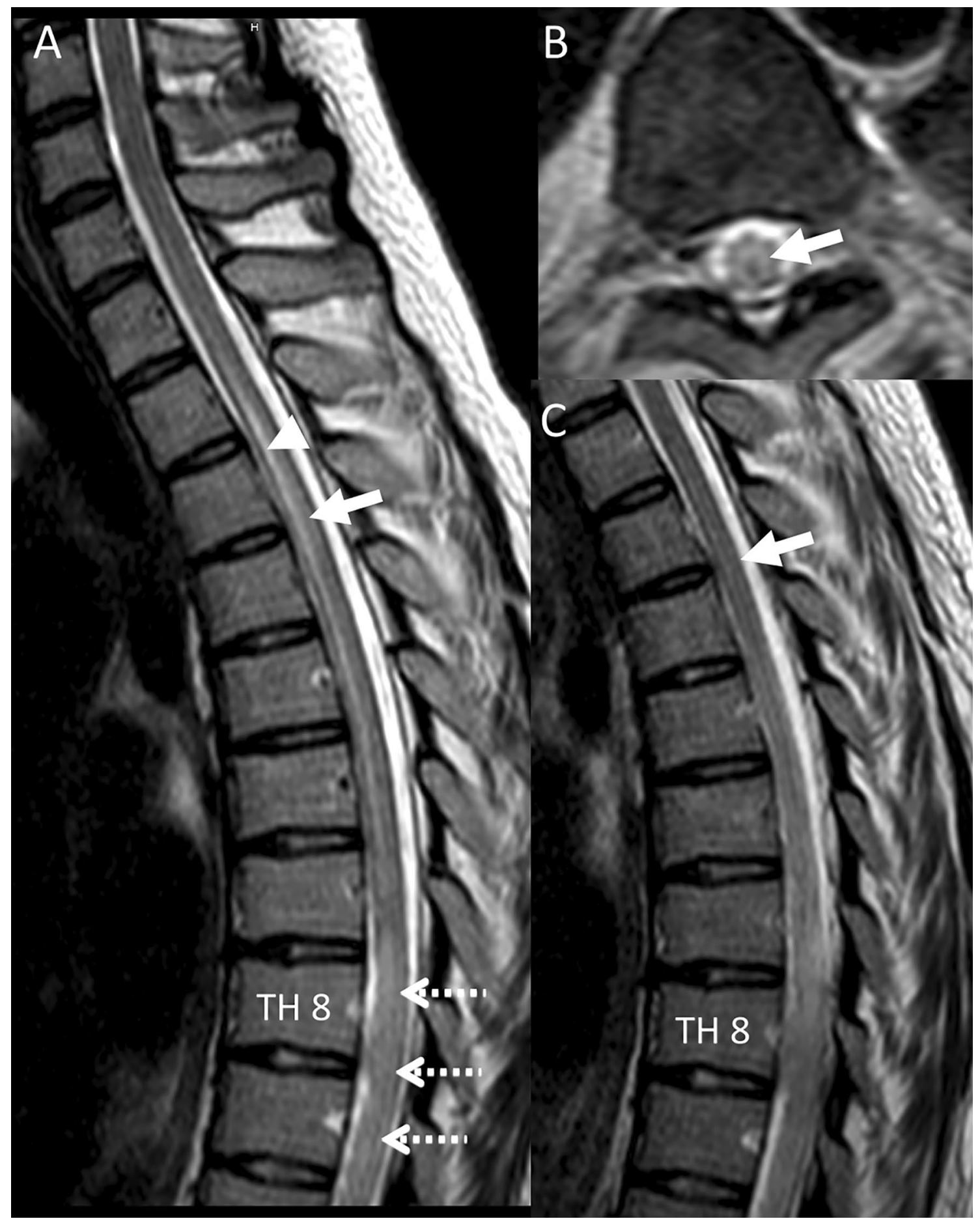

Fig. 2 Spinal MRI shows longitudinal thoracic myelitis. Spinal MRI $(1.5 \mathrm{~T}, \mathrm{~T} 2 \mathrm{w})$ revealed longitudinal centrally located $\mathrm{T} 2 \mathrm{w}$ signal intensities throughout the thoracic myelon (A, lucencies marked by white arrow on sagittal images) indicating an extensive thoracic myelitis with maximal extent at TH7-10 on axial (B, 1 week later) and sagittal (C) T2w images. In the acute stage (A), the central canal (white arrowhead) was slightly enlarged in the thoracic myelon (A) above the maximal swelling at Th7-10 (white dashed arrows) which slightly reversed on follow-up MRI (1 week later; B, C). However, severe longitudinal myelitis persisted $(\mathbf{C})$; note the centrally located inflammation of the thoracic myelon on the axial slice $(\mathbf{B})$ 


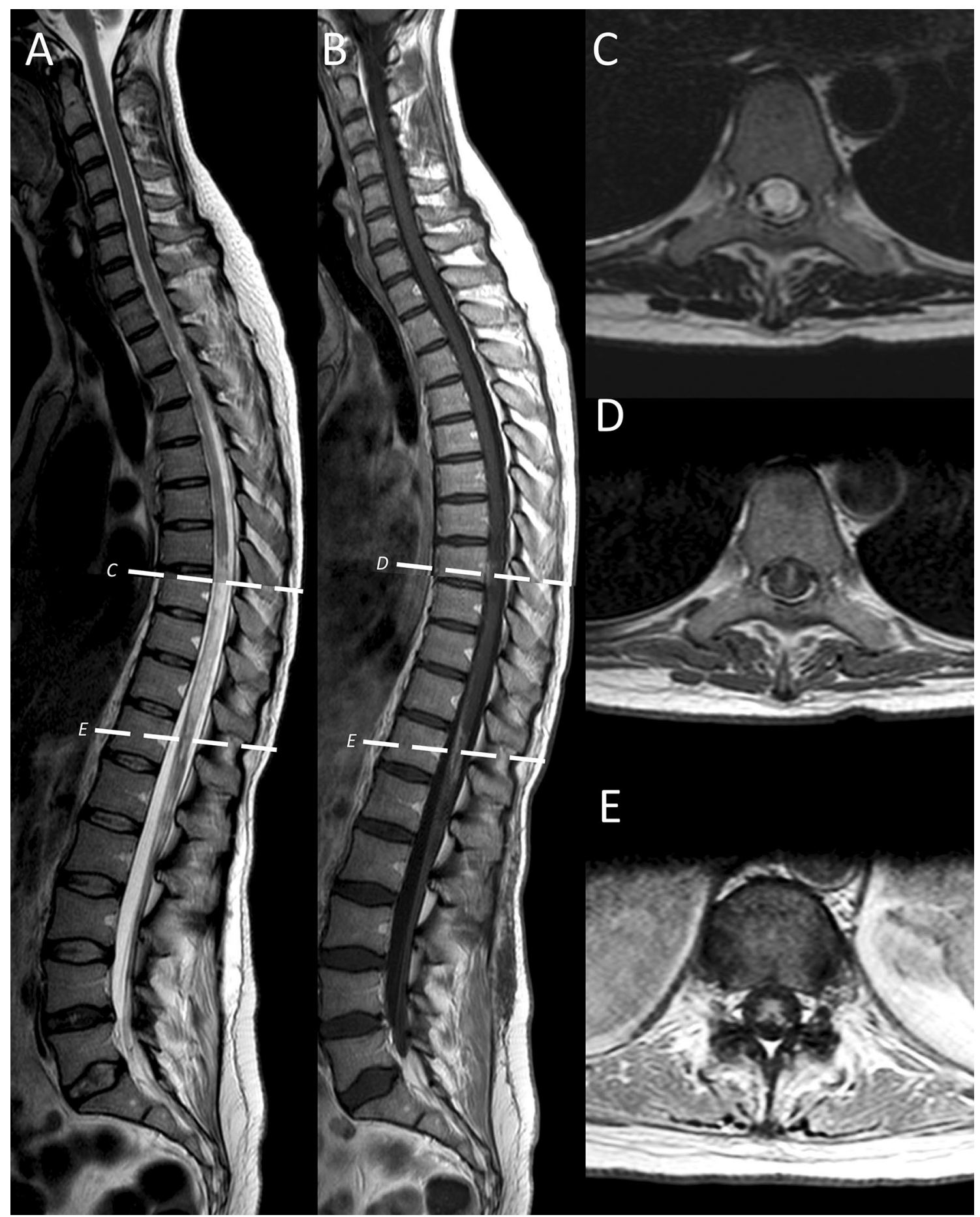

Fig. 3 Two months after subacute onset follow-up spinal MRI (no steroid therapy) shows severe chronic LETM with still some active inflammation at the same sites. From left to right: compared to the images at subacute onset (Fig. 2; with steroids) sagittal spinal MRI $(1.5 \mathrm{~T}, \mathrm{~T} 2 \mathrm{w})$ revealed much stronger and more extensive longitudinal $\mathrm{T} 2 \mathrm{w}$ signal intensities (A) throughout the thoracic myelon from

autoantibody panel was negative including those targeting myelin oligodendrocyte glycoprotein [MOG, assessed via
Th7 to the conus, and in (B) stronger enhancement in the conus and at TH8 in the T1w images with contrast. The transverse slices on the right show the corresponding slices at the level of TH8 and the conus indicated by the white hatched lines in the sagittal images. C Transverse T2w images; D, E transverse T1w images with contrast at the levels indicated in the sagittal slices

life-cell-assay [2] and confirmed via indirect immuno-fluorescence testing with MOG-transfected HEK-293 cells in 
another reference lab (EUROIMMUN, Lübeck, Germany)], glial fibrillary acid protein (GFAP), flotillin and AQP4 (in serum and CSF). She was tested negative for acute responses to several virus antigens (herpes simplex HSV1/2, varicella zoster virus, Epstein-Barr, German measles, mumps, and rubella) and bacteria (borrelia burgdorferi, mycoplasmas, and syphilis). Serological testing for antinuclear and antiphospholipids antibodies were negative. Repetitive PCR tests for SARS-CoV-2 were negative. We refrained from SARS-CoV-2 antibody testing after prolonged plasmapheresis but there were no antibodies during sequential testing in 2020 until 2 weeks before symptom onset. The MRZ reaction was negative at the last lumbar punction.

In addition to steroids, she was treated with plasmapheresis and immunoadsorption with slight recovery of visual functions (recognition of motion but no objects) but paraplegia, loss of sensory function below T5, and incontinence persisted. Weekly follow-up examinations in CSF showed improved pleocytosis $(33 / \mu \mathrm{l} ; 48 / \mu \mathrm{l}$ with a switch to lymphocytic pleocytosis) but even further increased protein (up $4.9 \mathrm{~g} / \mathrm{l})$. NAT was continued. Two months after subacute onset, with even more improved visual acuity but unchanged paraplegia follow-up spinal MRI still revealed even stronger contrast enhancement in the thoracic myelon (at TH7-8) and in the conus, in the absence of steroids (Fig. 3). Moreover, the longitudinal $\mathrm{T} 2 \mathrm{w}$ signal intensities in the thoracic myelon down to the conus became more intense and homogenous (Fig. 3). Cranial MRI did not show contrast enhancement and the signal intensities in the chiasm almost disappeared. CSF, however, improved and did not show lymphocytic pleocytosis any longer $(4 / \mu \mathrm{l})$ with still elevated but improved protein $(1 \mathrm{~g} / \mathrm{l})$.

Although potentially co-incidental, we have to consider the vector-based anti-SARS-CoV-2 vaccine as a main cause or at least a trigger of the severe clinical course in this RRMS patient for the following reasons:

The onset of symptoms 2 weeks after the vaccination is in line with a dysimmunological response phenotypically presenting with optic/chiasm neuritis and LETM resembling NMOSD. There was no evidence for a previously unrecognized NMOSD [3]. Transverse myelitis (TM) and LETM have been described in patients suffering from COVID-19 [7] but repetitive tests for SARS-CoV-2 were negative in our patient. A recent meta-analysis of adverse events across different vaccines against COVID-19 revealed a very low risk $(1 / 10,000)$ of TM in the general population [5]. TM has not been reported in MS patients treated with BNT162b2 vaccine (Pfizer-BioNTech COVID-19) injections [1] but there were 3 patients in the safety register of the approval study of the vector-based COVID-19 Vaccine ${ }^{\circledR}[7,9]$. One of them turned out to suffer from a previously unrecognized MS.

The nearly concurrent manifestation of chiasm and longitudinal myelitis argues against a relapse of RRMS. It may be speculated that the intended B cell response targeting the vector-based anti-SARS-CoV-2 vaccine triggered a dysimmunological process with a possibly pre-existing B cell pathoimmunology, with an ADEM-like excessive activity. In antibody-driven NMOSD, peripheral plasma cells are the source for AQP4-ab crossing the disrupted blood-brain barrier targeting astrocytes. NAT usually leads to activation and accumulation of $\mathrm{B}$ cells in the peripheral blood but prevents immune cells from crossing the (intact) blood-brain barrier. NAT could have induced catastrophic disease activity in this AQP4-ab negative NMOSD-like syndrome [8]. However, as this had not occurred during 10 years of regular NAT treatment, NAT is unlikely to be the cause for the acute LETM.

Our case suggests that the vector-based COVID-19 vaccine should not be used in RRMS if mRNA vaccines are available.

Author contributions $\mathrm{CH}$ : design or conceptualization of the study; analysis or interpretation of the data, drafting the manuscript; GB: acquisition and analysis of the data; RM: acquisition and analysis of the data; revising the manuscript for intellectual content; KH and HW: revising the manuscript for intellectual content; TB: acquisition and analysis of the data; revising the manuscript for intellectual content.

Funding Open Access funding enabled and organized by Projekt DEAL.

\section{Declarations}

Conflicts of interest The authors report no competing interest.

Open Access This article is licensed under a Creative Commons Attribution 4.0 International License, which permits use, sharing, adaptation, distribution and reproduction in any medium or format, as long as you give appropriate credit to the original author(s) and the source, provide a link to the Creative Commons licence, and indicate if changes were made. The images or other third party material in this article are included in the article's Creative Commons licence, unless indicated otherwise in a credit line to the material. If material is not included in the article's Creative Commons licence and your intended use is not permitted by statutory regulation or exceeds the permitted use, you will need to obtain permission directly from the copyright holder. To view a copy of this licence, visit http://creativecommons.org/licenses/by/4.0/.

\section{References}

1. Achiron A, Dolev M, Menascu S, Zohar DN, Dreyer-Alster S, Miron S, Shirbint E, Magalashvili D, Flechter S, Givon U, Guber D, Stern Y, Polliack M, Falb R, Gurevich M (2021) COVID-19 vaccination in patients with multiple sclerosis: what we have learnt by February 2021. Mult Scler 27:864-870

2. Di Pauli F, Mader S, Rostasy K, Schanda K, Bajer-Kornek B, Ehling R, Deisenhammer F, Reindl M, Berger T (2011) Temporal dynamics of anti-MOG antibodies in CNS demyelinating diseases. Clin Immunol 138:247-254

3. Gahlen A, Trampe AK, Haupeltshofer S, Ringelstein M, Aktas O, Berthele A, Wildemann B, Gold R, Jarius S, Kleiter I (2017) 
Aquaporin-4 antibodies in patients treated with natalizumab for suspected MS. Neurol Neuroimmunol Neuroinflamm 4:363

4. Kim HJ, Paul F, Lana-Peixoto MA, Tenembaum S, Asgari N, Palace J, Klawiter EC, Sato DK, de Seze J, Wuerfel J, Banwell BL, Villoslada P, Saiz A, Fujihara K, Kim SH, Guthy-Jackson Charitable Foundation NMOICC, Biorepository (2015) MRI characteristics of neuromyelitis optica spectrum disorder: an international update. Neurology 84:1165-1173

5. Li X, Ostropolets A, Makadia R, Shaoibi A, Rao G, Sena AG, Martinez-Hernandez E, Delmestri A, Verhamme K, Rijnbeek PR, Duarte-Salles T, Suchard M, Ryan P, Hripcsak G, Prieto-Alhambra D (2021) Characterizing the incidence of adverse events of special interest for COVID-19 vaccines across eight countries: a multinational network cohort study. medRxiv. https://doi.org/10. $1101 / 2021.03 .25 .21254315$

6. Nightingale H, Witherick J, Wilkins A (2011) Diagnosis of longitudinally extensive transverse myelitis. BMJ Case Rep. https:// doi.org/10.1136/bcr.10.2010.3444

7. Roman GC, Gracia F, Torres A, Palacios A, Gracia K, Harris D (2021) Acute transverse myelitis (ATM): clinical review of 43 patients with COVID-19-associated ATM and 3 post-vaccination ATM serious adverse events with the ChAdOx $1 \mathrm{nCoV}-19$ vaccine (AZD1222). Front Immunol 12:653786

8. Traub J, Hausser-Kinzel S, Weber MS (2020) Differential effects of MS therapeutics on B cells-implications for their use and failure in AQP4-positive NMOSD patients. Int J Mol Sci 21(14):5021. https://doi.org/10.3390/ijms21145021

9. Voysey M, Clemens SAC, Madhi SA, Weckx LY, Folegatti PM, Aley PK, Angus B, Baillie VL, Barnabas SL, Bhorat QE, Bibi
S, Briner C, Cicconi P, Collins AM, Colin-Jones R, Cutland CL, Darton TC, Dheda K, Duncan CJA, Emary KRW, Ewer KJ, Fairlie L, Faust SN, Feng S, Ferreira DM, Finn A, Goodman AL, Green CM, Green CA, Heath PT, Hill C, Hill H, Hirsch I, Hodgson SHC, Izu A, Jackson S, Jenkin D, Joe CCD, Kerridge S, Koen A, Kwatra G, Lazarus R, Lawrie AM, Lelliott A, Libri V, Lillie PJ, Mallory R, Mendes AVA, Milan EP, Minassian AM, McGregor A, Morrison H, Mujadidi YF, Nana A, O'Reilly PJ, Padayachee SD, Pittella A, Plested E, Pollock KM, Ramasamy MN, Rhead S, Schwarzbold AV, Singh N, Smith A, Song R, Snape MD, Sprinz E, Sutherland RK, Tarrant R, Thomson EC, Torok ME, Toshner M, Turner DPJ, Vekemans J, Villafana TL, Watson MEE, Williams CJ, Douglas AD, Hill AVS, Lambe T, Gilbert SC, Pollard AJ, Oxford CVTG (2021) Safety and efficacy of the ChAdOx1 nCoV-19 vaccine (AZD1222) against SARS-CoV-2: an interim analysis of four randomised controlled trials in Brazil, South Africa, and the UK. Lancet 397:99-111

10. Wingerchuk DM, Banwell B, Bennett JL, Cabre P, Carroll W, Chitnis T, de Seze J, Fujihara K, Greenberg B, Jacob A, Jarius S, Lana-Peixoto M, Levy M, Simon JH, Tenembaum S, Traboulsee AL, Waters P, Wellik KE, Weinshenker BG, International Panel for NMOD (2015) International consensus diagnostic criteria for neuromyelitis optica spectrum disorders. Neurology 85:177-189

11. Wu Y, Zhong LM, Geng J (2019) Neuromyelitis optica spectrum disorder: pathogenesis, treatment, and experimental models. Mult Scler Relat Dis 27:412-418 